\title{
LOS GRABADOS RUPESTRES DEL BARRANCO DE TEJELEITA, VALVERDE, EL HIERRO, ISLAS CANARIAS
}

\section{THE BARRANCO DE TEJALEITA ROCK ART (VALVERDE, EL HIERRO, CANARY ISLANDS)}

\author{
por \\ Mª DE LA CRUZ JIMÉNEZ GÓMEZ
}

\begin{abstract}
RESUMEN Se presentan, por primera vez, la totalidad de grabados aborígenes del Barranco de Tejeleita (Valverde); éstos se contextualizan en un importante conjunto de manifestaciones rupestres de la zona noreste de la isla de El Hierro. Se describen las características técnicas y tipológicas de 3 categorías de formas: geométricas, figurativas y alfabéticas que coexisten en un mismo panel. Del análisis de los contextos arqueológicos y medioambientales en los que se encuentran se concluye en la relación que éstos guardan con el mundo funerario y con el agua, en este último caso, se inscriben en un territorio en el que los textos antiguos señalan que habitaba una de las divinidades que los bimbaches llamaban "Aranfaybo" que intervenía en los ritos propiciatorios de la lluvia.
\end{abstract}

\begin{abstract}
For the first time the whole known collection of aborigen rock art from the "barranco" of Tejeleita, are presented; these are joined in an important group of rock art in the north east of the island of El Hierro. The techniques and typological characteristics of three categories of shape are presented: geometric, figurative and alphabetic that coexist in the same panel. From the analysis of the arqueological and environmental contexts in which they are found it is concluded that in relation that these have with the undertakers world and with water, in the latter they are inscribed in a territory in which, the ancient texts indicate, live one of the divinities that the "bimbaches" called "Aranfaybo" who intervened in the propitiatory rites of rain.
\end{abstract}

Palabras claves Prehistoria de El Hierro. Manifestaciones rupestres. Ritos de lluvia. Bimbaches.

Key words Prehistory of El Hierro. Rock Art Sites. Rain Ritual. Bimbaches. 


\section{ANTECEDENTES}

El Barranco de Tejeleita es conocido como enclave de manifestaciones rupestres desde finales del siglo XIX, momentos en los que el capitán Benigno Domínguez explora este barranco localizando varias inscripciones alfabéticas que fueron estudiadas y publicadas por R. Verneau (1887).

Con posterioridad los estudios sobre las manifestaciones rupestres de la isla, o del Archipiélago Canario en general, las han incluido en sus inventarios. Son de gran interés las investigaciones de J. Álvarez Delgado (1964) que incluyen parte del inventario y un estudio de algunas de las inscripciones líbico-bereberes de este barranco, proponiendo la posible transcripción y equivalencia de los signos alfabéticos con signos y voces de la lengua bereber. Es a finales de la década de los años setenta, dentro del proyecto de investigación sobre la prehistoria de El Hierro, cuando prospectamos de forma sistemática Tejeleita con el objetivo de inventariar este conjunto rupestre.

\section{EL BARRANCO DE TEJELEITA}

La estación de Tejeleita se contextualiza en un importante conjunto rupestre de un sector de la vertiente noreste de la isla que se extiende, a modo de cuña triangular, entre la costa y Valverde. Está delimitado, de N. a S, entre costa y la Villa de Valverde; en la línea costera, entre la Punta del Jorado y la Punta Roque del Palo; su lado N. sigue la proyección diagonal desde Punta del Jorado hasta Valverde; mientras que su flanco septentrional media entre la proyección de la Punta Roque del Palo pasando por Montaña Ribera para morir en Valverde, a los $600 \mathrm{~m}$. de altitud (fig. 1)

Es a lo largo de esta zona donde, también, se emplazan los barrancos de mayor entidad fisiográfica de la isla, formaciones que revisten un doble interés en el presente trabajo, tanto desde el punto de vista ecológico como arqueológico.

El barranco que nos ocupa está integrado por tres accidentes articulados entre sí: los Barranquillos de La Aguililla y de Camino Ancho que desembocan, a la altura de los $325 \mathrm{~m}$, en el barranco de Tejeleita formando un solo cauce conocido por este nombre hasta su desembocadura. El cauce tradicionalmente conocido por Tejeleita, como ya se indicó, tiene su origen en la confluencia de dos pequeños barranquillos de Camino Ancho y de La Aguililla, al pié de la Cuesta de Cayetano y al E. de la Montaña Ribera para, después de atravesar la Loma del Zapatero, desembocar al mar por la Playa de La Caleta en un recorrido de $1.800 \mathrm{~m}$. En el tramo superior, comprendido entre la confluencia de los citados barranquillos y el trazado de la carretera general L-870, sus características fisiográficas experimentan ligeras variaciones, con suave relieve en sus inicios para ir alcanzando progresivamente profundidad en las inmediaciones del tramo medio. Es en las proximidades de este límite donde el cauce se hace un poco más profundo, con saltos de agua de escasa entidad; y donde sus márgenes poseen algunos covacho colmatados de material de arrastre y vegetación. Desde un punto de vista arqueológico hay que destacar que se trata de un tramo de gran pobreza de manifestaciones rupestres, registrándose tan solo una de las estaciones conocidas hasta el momento.

El curso medio se inicia a partir del trazado de la referida vía y es donde el barranco adquiere una mayor altura e irregularidad. A lo largo de este el cauce se interrumpe por 8 saltos de agua, escarpados y profundos, que se suceden hasta la desembocadura. A su pie se localizan las correspondientes maretas que a modo de profundos charcas fueron labradas por la intensa erosión del agua que produce la gran altura de estos quiebros del cauce.

Sus márgenes están constituidas por un estrato de basalto que, en ocasiones, se superpone a materiales arcillosos o cenizas volcánicas compactas; a lo largo de su irregular discurso se quiebran en repetidas ocasiones, a veces coincidiendo con los referidos saltos de agua, formando auténticos roques. También, siempre a la altura del estrato superior, se abren algunas cuevas de cierta entidad, el lugar elegido para 
ejecutar los grabados rupestres. Estos solo aparecen, con una sola excepción, en la margen izquierda, o flanco norte, orientados al sotavento, que al abrigo de los vientos dominantes se encuentran libres de líquenes y otras comunidades vegetales que impiden tanto ejecutarlos como poder ser vistos y, en consecuencia, cumplir el fin para el que fueron concebidos.

Características similares presenta el Barranquillo de la Aguililla que nace a los $410 \mathrm{~m}$. de altitud por la ladera occidental de la Cuesta de Cayetano, cuyo cauce se rompe en varios saltos de agua en las proximidades de su confluencia con los de Camino Ancho y Tejeleita. Un poco más arriba, a los $450 \mathrm{~m}$., y las proximidades de la Cueva de La Pólvora, nace Camino Ancho, con características similares, su cauce discurre paralelo al anterior.

Un último elemento a destacar en este barranco, teniendo en cuenta las limitaciones que impone la orografía, es el antiguo camino que parte de La Caleta y después de unirse, a escasa distancia y en torno a los 100 m.s.n.m. con el camino que viene desde el Tamaduste, asciende por la margen derecha de Tejeleita, se encaja en la Cuesta de Cayetano y muere en Valverde tras experimentar una bifurcación hacia la zona de la Cueva de la Pólvora, por la izquierda, y hacia S. Juan por la derecha coincidiendo con el trazado de la actual carretera genera, en la entrada de la Villa.

Teniendo en cuenta estas características, su pertenencia a un mismo nicho ecológico y la similitud de los vestigios arqueológicos que encierra en su interior (grabados rupestres con características de ubicación, ejecución y morfología similares) entendemos que el conjunto del barranco debe valorarse desde el punto de vista cultural como una unidad inseparable, usado por las mismas gentes y con unos mismos fines en toda su extensión. Cualquier disociación que se plantee de su contenido arqueológico conllevaría siempre desenfocar la valoración o valoraciones de tipo cultural que puedan plantearse, como efectivamente ha venido sucediendo al considerar la estación de La Caleta como un mundo aparte, en base a la gran entidad que revisten los grabados que allí existen, a su ubicación junto al mar y, también, al desconocimiento del propio barranco, tema sobre el que más adelante volveremos (Jiménez Gómez 1996c).

\section{INVENTARIO}

Las estaciones rupestres que se describen las hemos denominado utilizando la toponimia del cauce en el que se ubican. Para facilitar su descripción y análisis hemos creído oportuno denominar estación a cada uno de los enclaves donde se concentran conjuntos de grabados distantes entre sí, organizados en uno o varios paneles. La realizamos siguiendo la dirección cumbre-costa, iniciándola por los barranquillo de Camino Ancho y de La Aguililla, para continuar con el cauce de Tejeleita, propiamente dicho.

Con objeto de reunir la totalidad de manifestaciones y conseguir una visión del conjunto rupestre del barranco hemos adjuntado a nuestro inventario algunas estaciones, hoy desaparecidas, que habían sido publicados con anterioridad. Así mismo, incluimos nuevos hallazgos no catalogados por nosotros, indicamos sólo en ambos casos la fuente bibliográfica de procedencia.

\section{Camino Ancho.}

ESTACIÓN $N^{\circ} 1$.

Panel $n^{\circ} 1$.

Situación: en la cornisa de una cueva natural, ubicada en las proximidades del lecho, junto a un salto de agua; su entrada está orientada al Sur, de planta irregular de unos $4,5 \mathrm{~m}$ por $3 \mathrm{~m}$ de largo y ancho, respectivamente, alcanzado $1 \mathrm{~m}$ de altura.

Está compuesta por un solo panel, con las siguientes características: 
Dimensiones: $25 \times 8 \mathrm{~cm}$. Técnica: picado muy superficial. Orientación: S.E.

Descripción: inscripción líbico-bereber compuesta por 4 signos dispuestos en una sola línea de secuencia vertical (Fig. 2,a).

Observaciones: la escasa profundidad del picado la erosión natural motiva que este panel sea prácticamente imperceptible, hoy solo visible por un leve cambio en la tonalidad ocre que posee el basalto que le sirve de soporte.

\section{ESTACIÓN N ${ }^{\circ} 2$.}

Panel $n^{\circ} 1$.

Situación: en la margen derecha del barranco, en las proximidades de la confluencia con los barrancos de La Aguililla y Tejeleita, en una pared constituida por una disyunción prismática que forma una losa casi vertical. Los grabados están ejecutados en una zona de color negruzco de unos $30 \mathrm{~cm}$. de ancho causada, al parecer, por la circulación continua de agua, haciéndola visible a gran distancia.

Está compuesta por un solo panel de las siguientes características:

Dimensiones. 37 X $32 \mathrm{~cm}$. Técnica: picado Orientación: NW

Descripción: inscripción líbico-bereber compuesta por 20 signos dispuestos en dos líneas de secuencia vertical: una línea integrada por 18 signos mientras la situada a su izquierda solo tiene 2 signos (Fig.7,a).

Observaciones: Se trata de la inscripción de mayor longitud conocida hasta el momento en Canarias. En ella existen dos formas, las $\mathrm{n}^{\circ} 1$ y 3 comenzando por la parte superior de la línea, que no eran conocidos entre los signos herreños, canarios y alfabetos líbico-bereberes, en general. Uno de los autores (R. Springer Bunk), interpreta que podría obedecer, en el primero de los casos, a la posible unión de los caracteres //I $\mathrm{O} ; \mathrm{y}$, una distorsión involuntaria; en el trazado del segundo signo, producida por una anomalía en el proceso de su ejecución. Esta inscripción se encuentra alterada por un rayado reciente realizado en su interior.

Bibliografía: Ruiz González et al. (2000: 43-46).

\section{Barranco de La Aguililla}

El inventario lo compone una sola estación, compuesta por un panel de las siguientes características:

Situación: en la cornisa de una de las dos cuevas contiguas que se abren en la zona alta de la margen izquierda, junto a un gran salto de agua de las inmediaciones de la confluencia con el cauce de Tejeleita. La fachada de ambas oquedades ocupa unos $30 \mathrm{~m}$. lineales a lo largo de esta margen, siendo la del extremo suroriental la que posee manifestaciones rupestres. Se trata de una gran oquedad de planta irregular, mide $10 \mathrm{~m}$. de largo por 6 de profundidad, en sus extremos mayores, y unos $2 \mathrm{~m}$. de alto máximo. La entrada se encuentra cubierta por grandes bloques procedentes del desplome de la zona alta de esta pared.

Está compuesta por un solo panel que presenta las siguientes características:

Dimensiones: 160x60 cm. Técnica: picado, repicado y rayado. Orientación: $S$.

Descripción: Composición integrada por 3 tipos de signos (Fig. 3):

1. Signos alfabéticos, ejecutados por picado, que se sitúan en pequeños grupos a la derecha e izquierda de la parte superior del panel.

2. Motivos geométricos, ejecutados por picado, que se entrelazan formando una composición de tipo laberíntico ocupando la zona central y destacando sobre el resto.

3. Motivos figurativos: representados por óvalos geminados simples, o con un trazo ondulado que se proyecta hacia el exterior, ocupan la zona alta a ambos lados del panel. 
4. Motivos lineales que se superponen a los anteriores, ejecutados mediante una rayado superficial, y que parecen corresponder al velamen de varias embarcaciones.

Observaciones: No es posible contabilizar el número de signos alfabéticos seguros debido a las dificultades que presenta su morfología, con formas similares a los signos denominados geométricos. La estación se encuentra en la actualidad muy alterada debido a la agresión recibida hace unos años en la que se rayó totalmente la superficie alterando por completo el surco original de los grabados.

\section{Barranco de Tejeleita.}

Las estaciones rupestres catalogadas se concentran especialmente a partir del curso medio, en las proximidades de la interrupción que ocasiona el trazado de la carretera L- 870 que asciende hasta Valverde. Solo ha sido localizada una estación en la zona próxima a la desembocadura, aunque a cierta distancia de la conocida estación de La Caleta (Jiménez Gómez 1996c).

El inventario que presentamos responde a los trabajos efectuados por nosotros, no obstante J. Álvarez Delgado (1964) aporta un conjunto de inscripciones que en la actualidad no existen, que pudieron haber desaparecido por las obras de la mencionada carretera, en la década de los años 40 momentos en los que éste se prospectó el barranco.

\section{ESTACIÓN $N^{\circ} 1$.}

Se emplaza, según la información publicada, frente a la Montaña Ribera), en la margen izquierda del barranco y está compuesta por 2 paneles que se ubican en la superficie de disyunciones prismáticas que a modo de afloramiento rocoso se disponen verticalmente en el borde superior del barranco antes de alcanzar la cima.

\section{Panel $n^{\circ} 1$.}

Situación: a unos $500 \mathrm{~m}$. de la estación n ${ }^{\circ} 2$ de Camino Ancho y a unos $40 \mathrm{~m}$. del panel $\mathrm{n}^{\circ} 2$.

Dimensiones: 80 X 49. Técnica: incisa. Orientación: SE

Descripción: inscripción líbico-bereber compuesta por 5 signos dispuestos en secuencia vertical (Fig.7,b).

Observaciones: pese a la novedad de la técnica incisa, los signos contenidos en esta inscripción son similares a los ya conocidos en otras estaciones herreñas.

\section{Panel $n^{\circ} 2$.}

Situación: la descrita anteriormente. Dimensiones: 80 X $90 \mathrm{~cm}$. Técnica: incisa. Orientación: S.

Descripción: inscripción líbico-bereber compuesta por diez signos que se disponen en 3 líneas de secuencia vertical (Fig.7, c).

Bibliografía: Ruiz González et al. (2000: 41-42).

\section{ESTACIÓN N 2.}

Se emplaza en un roque, constituido por un afloramiento basáltico de tipo columnar, que se eleva en la margen izquierda en el arranque de la Loma del Zapatero y en la zona alta del primer salto de agua que 
se registra en este tramo. La estación forma parte de un conjunto más amplio que se congrega en sus alrededores que presentamos individualmente para su mejor descripción.

Está compuesta por 5 paneles bien diferenciados por su técnica de hechura, ubicación y tipo de motivos grabados.

Panel $n^{o} 1$.

Situación: en la zona alta del roque, a unos 3,5 m del lecho. Dimensiones: 36,5 x 22,5 cm. Técnica: picado. Orientación: SW.

Descripción: inscripción líbico-bereber compuesta por 15 signos dispuestos en dos líneas de secuencia vertical (Fig.2,b).

Observaciones: Por su ubicación e inaccesibilidad se hace notar la dificultad de elaboración de esta inscripción, lo que también ha motivado su buen estado de conservación. El calco obtenido por nosotros posee 2 signos que no parecen la reproducida por J. Álvarez Delgado (1960: 414, fig.78b).

Paneles $n^{\circ} 2$ y 3 .

Situación: en la pared que ocupa la parte baja del roque. Técnica: rayado. Orientación: SW.

Descripción: composición de motivos de diversa morfología:

1. Naviformes de diversa tipología, con indicación de mástiles y velas. 2.Haces de líneas que parecen pertenecer a mástiles de otras naves desaparecidas. 3.Grafías latinas (Andrés) (Figs. 5a y 6b).

Observaciones: el soporte muestra superficies de color ocre vivo que revela haber sido la superficie subyacente de una columna, desprendida en fechas recientes, que formaba parte del roque.

\section{Panel $n^{\circ} 4$.}

Situación: bloque suelto, exento, al pié del mismo roque, posiblemente desprendido. Dimensiones: $56 \mathrm{x}$ $28 \mathrm{~cm}$. Técnica: rayado.

Descripción: caracteres latinos en los que se lee el nombre Andrés en 2 ocasiones, y parte del mismo, en una tercera. Se combina con un motivo geométrico no identificable (Fig. 5b).

Panel $n^{\circ} 5$.

Situación: en bloque suelto, exento, que se encontraba en las proximidades del mismo roque, sin que pueda conocer su posición original.

Dimensiones: 80 x 40,5 cm. Técnica: picado. Orientación: desconocida

Descripción: caracteres alfabéticos dispuestos en 3 líneas de secuencia vertical en la que se contabiliza un total de 10 signos, algunos de ellos unidos entre sí (Fig. 2c).

Observaciones: se trata de un bloque que extrajo de su lugar de origen un vecino de Valverde y que nos entregó en 1985 para depositarlo en el Cabildo insular; posteriormente este fue destruido por operarios de este Organismo. Este panel consta en el inventario de J. Álvarez Delgado (1964: 416, fig. 81d), donde hay varias modificaciones respecto al calco realizado por nosotros. 


\section{ESTACIÓN N 3.}

Se ubica a unos $250 \mathrm{~m}$ de distancia de la anterior, junto al $2^{\circ}$ salto de agua del barranco; a su pié se abre una gran mareta que retiene el agua largo tiempo. La estación está compuesta por 2 paneles que se ubican en la cornisa de una cueva, a unos $3 \mathrm{~m}$ de altura del nivel del suelo.

Panel $n^{o} 1$.

Situación: en una cueva natural que se abre en la zona media-alta de la margen izquierda del barranco. Su entrada se abre a todo lo largo de la línea de este flanco, está orientada al sur; su planta irregular es de escasa profundidad. Dimensiones: 85 x $68,2 \mathrm{~cm}$.

Técnica: picado. Orientación: SE. Descripción: composición integrada por 3 tipos de signos dispuestos en trazado diagonal (Fig. 4b):

1. Signos geométricos: suponen el mayor porcentaje de los motivos que aparecen en este panel. Se trata de motivos circuliformes que en ocasiones experimentan irregularidades: trazos o puntos internos. Constituyen un conjunto que se agrupa en la zona superior derecha del panel.

2. Motivos figurativos:

A. Zoomorfos: interpretamos como tal el motivo que se ubica en el ángulo inferior izquierdo del panel, guarda gran semejanza con otros aparecidos en estaciones cercanas, así como en los grabados rupestres norteafricanos en los que se interpreta de esta misma forma.

B. Podomorfos: interpretamos así un conjunto de óvalos geminados o círculos que muestran apéndices que se prolongan hacia el exterior.

3. Motivos alfabéticos: inscripción constituida por 14 signos alfabéticos dispuestos en 3 líneas en secuencia vertical, así como individualizados entre las líneas 1 y 2 , y el extremo derecho de la línea 3.

Observaciones: La alteración antrópica ejercida sobre este panel y la escasa profundidad que presenta el picado dificultan el calco y lectura correcta del mismo, como puede observarse en las diferencias existentes entre la reproducción que hace J. Álvarez Delgado (1964: 315, fig. nº $^{\circ}$ b) y la que nosotros catalogamos.

\section{Panel $n^{\circ} 2$.}

Situación: en la cornisa de una cueva que se encuentra a unos $30 \mathrm{~m}$ de distancia de la anterior. Se trata de una oquedad natural, de planta irregular, que mide unos $15 \mathrm{~m}$ de ancho por $9 \mathrm{~m}$ de profundidad.

Dimensiones: $18 \times 22 \mathrm{~cm}$. Técnica: picado muy superficial.

Orientación: SE. Descripción: inscripción constituida por 13 signos alfabéticos dispuestos en 3 líneas de secuencia vertical (Fig. 4a)

Observaciones: debido a la superficialidad del picado existen dificultades de calco y descripción del panel, manifiesta en las contradicciones existentes entre la figura catalogada por nosotros y la reproducida por J. Álvarez Delgado (1964: 415, fig. nº 80a).

\section{ESTACIÓN N ${ }^{\circ} 4$.}

Agrupamos en esta estación un conjunto de 8 paneles con inscripciones que se encontraban grabadas en las inmediaciones de esta zona, que en la actualidad han desaparecido. Sus características fueron recogidas en el inventario de J. Álvarez Delgado (1964: 414-416); las utilizamos como base para completar la descripción del conjunto rupestre del barranco. De ellas solo conocemos que 6 se emplazaban en cornisas de cuevas (Figs. 7, d-i), y las restantes en las paredes de las márgenes del barranco (Fig. 8. B y C). 


\section{ESTACIÓN N 5.}

Situación: a unos $100 \mathrm{~m}$ de distancia de la estación anterior, en una de las paredes rocosas del estrato superior de la misma margen del barranco. Está compuesta por un panel con las siguientes características:

Dimensiones: 66 x $42 \mathrm{~cm}$. Técnica: picado. Orientación S.

Descripción: motivos naviformes esquematizados, con indicación de mástiles y velas (fig. 6a).

\section{ESTACIÓN N ${ }^{\circ} 6$.}

Situación: a un centenar de metros de la costa, en la zona alta de la pared de la misma margen izquierda, junto a un pozo de agua. Está compuesta por un solo panel con las siguientes características:

Dimensiones: 27 x $5 \mathrm{~cm}$. Orientación: SE. Técnica: picado muy superficial.

Descripción: inscripción compuesta por 8 caracteres alfabéticos dispuestos en una línea de secuencia vertical (Fig. 2d).

\section{Soportes, Técnicas y motivos}

Los grabados rupestres de El Hierro se ejecutaron, salvo dos excepciones, al aire libre. Todas las estaciones tienen en común, entre otros, el tipo de soporte; es decir, superficies rocosas de naturaleza basáltica lisas y compactas seleccionadas en sitios desde donde pudieran ser vistas. Una de las razones de esta selección, quizás la única de la que podemos estar seguros, es la orientación en la que se encontraban estos soportes: al resguardo de los vientos y lluvias dominantes, y por tanto desprovistas de la humedad que hace crecer líquenes y comunidades vegetales rupícolas que, además de facilitar su ejecución, se aseguraba que en el transcurso del tiempo estos no quedaran ocultos y continuaran siendo vistas por la población

Las técnicas de ejecución de estos grabados son, básicamente, dos: picado y rayado, si bien en fechas recientes se ha dado a conocer una estación con grabados realizados mediante incisión (Ruiz González et al. 2000: 41). De estas destaca por su frecuencia de uso la del picado, que se practicó de forma continua $y$ discontinua, variante esta última que algunos autores también denominan puntillado. Ambas pueden encontrarse aisladas o formando parte de un mismo motivo; pero, también, se localizan asociadas en un mismo surco, como ocurre en la estación del Barranco de La Aguililla, modalidad conocida como repicado (Hernández Pérez 1981: 449). Es frecuente observar en ellos un trabajo poco intenso que frecuentemente se limita a picar la capa meteorizada de la roca de soporte, de escasos milímetros de espesor; con ello se conseguía sacar a la luz la capa subyacente y conseguir, de manera fácil, un mayor efecto visual de las formas grabadas ahora recortadas por el contraste de tonalidad conseguido en la coloración del soporte. Este es el caso de muchas de las estaciones que se recogen en el presente inventario.

De forma general para toda la isla puede argumentarse que la tipología que presentan los grabados aborígenes está representada por 3 conjuntos de motivos: geométricos, figurativos y formas alfabéticas, aislándose, especialmente en el primero, una gran variedad de signos, que se encuentran en toda su expresión en este barranco. Hasta la década de los años setenta sólo eran distinguidos dos tipos: geométricos y alfabéticos a los que añadimos, en 1996, lo que entendemos pueden considerarse formas figurativas aquí documentados. Motivos figurativos: representados aquí por 4 formas diferenciadas: podomorfos, zoomorfos, naviformes y cruciformes (Jiménez Gómez 1996: 265b)

- Podomorfos: concebidos en general dentro de las figuras geométricas, como simples figuras circulares u ovales, pero que nosotros interpretamos como huellas de pié o de calzado. Se trata de un conjunto de 
signos de tendencia circular u oval dividido en su interior por un trazo diametral que, en ocasiones, se complementa con un trazo lineal ondulado que se proyecta hacia el exterior. Su mejor expresión se localiza en el panel 1 de la estación $n^{\circ} 1$ de La Aguililla, y en el panel $n^{\circ} 1$ de la estación $n^{\circ} 3$ de Tejeleita, ya citados. - Zoomorfos: La dificultad interpretativa y el extremado esquematismo que caracteriza a los grabados solo permite plantear a modo de hipótesis la posibilidad de la presencia de un zoomorfo. Se trata de una figura compuesta por un trazo lineal horizontal, del que parten varios trazos cortos a modo de patas, y que es rematado en la parte superior de en uno de sus extremos por dos trazos curvos a modo de cabeza o cornamenta; su extremo opuesto está rematado por una composición de círculos entrelazados. Esta figura forma parte del panel 1, estación $\mathrm{n}^{\circ} 3$, de Tejeleita, integrado por una compleja composición.

- Naviformes: representados por un nutrido conjunto de embarcaciones dotadas de casco, mástiles, velas y algunos otros detalles. Se asocian a los conjuntos anteriores, en las estaciones $n^{\circ} 2$ y 6 de Tejeleita.

\section{ORIGEN, CRONOLOGÍA Y VALORACIÓN CULTURAL}

Las manifestaciones rupestres constituyen una de las muestras mejor representadas de la cultura aborigen herreña; desde los primeros hallazgos se plantearon diversas teorías acerca de su posible origen, significado y cronología. Debido al conocimiento que se tenía sobre los grabados se creía que las inscripciones líbicobereberes estaban mejor representadas en la zona nordoriental y las composiciones de geométricos lo estaban en la suroccidental de la isla, entendiéndose que se trataba de dos grupos étnicos diferenciados, coetáneos, asentados en la isla. Otras propuestas señalaron que los la población aborigen era la autora de los grabados geométricos, mientas que las inscripciones alfabéticas obedecían a la presencia de "invasores" (Verneau 1882: 286-87). Más tarde se atribuyeron estas últimas a forasteros mauritanos, navegantes y conquistadores que transitaban las costas isleñas con distintos objetivos; a la vez se relacionaron con las culturas protohistóricas norteafricanas, concretamente con la escritura líbico-bereber, planteando un origen común con estas culturas. A estos momentos obedecen también los intentos de lectura que se interpretaron como frases cortas, nombres propios o de filiación (Álvarez Delgado 1964: 393, 396).

En la actualidad las investigaciones arqueológicas no han encontrado vestigios arqueológicos que demuestren que haya existido en la isla una dualidad cultural y/o étnica; por el contrario ha corroborado, en la mayoría de las estaciones insulares, la coexistencia de motivos geométricos y formas alfabéticas en una misma estación e integrados en una misma composición. El incremento de los hallazgos y la constatación de estaciones en diferentes cotas de la orografía insular, en contextos claramente adscritos a la cultura aborigen, han cambiado sustancialmente el conocimiento y los enfoques sobre el tema. Sin embargo, la ausencia de superposiciones, de diferentes técnicas de ejecución, o distribuciones espaciales específicas de los grabados, no permiten aún fundamentar su posible cronología (Jiménez Gómez 1985-1987). Pese a las limitaciones para reconocer el significado de las estaciones rupestres, en los últimos años se ha avanzado considerablemente; los resultados obtenidos en la investigación han abierto nuevas vías de búsqueda para interpretar el conjunto rupestre insular.

En primer lugar el incremento del inventario de inscripciones alfabéticas ha conducido a un mejor conocimiento de sus características y procedencia. Hoy se acepta que en Canarias existieron dos alfabetos emparentados: el Canario Occidental y el Canario Oriental o Majo, admitiendo la posibilidad de que en cada isla existan signos exclusivos (Belmonte et alii. 1998: 17); y que las inscripciones canarias siguen ciertas normas escriturarias del líbico-bereber (Ruiz González et alii. 2000: 53).

Según esta misma fuente, las inscripciones herreñas junto con las de Gran Canaria se integran en el alfabeto Canario Occidental, con ligeras diferencias entre ambas islas. En lo que concierne al alfabeto de El Hierro, en la actualidad, está compuesto por 29 formas de signos, constatándose más de 320 recurrencias. 
Del análisis del grado de afinidad y parentesco en los diferentes alfabetos conocidos, se ha podido mostrar que el alfabeto Canario Occidental se emparenta con los alfabetos usados en la antigua Númidia, especialmente con el Masilio, en el noreste africano.

Una segunda vía de conocimiento procede del análisis de las estaciones rupestres en sus correspondientes contextos arqueológicos. Una primera conclusión, como ya se dijo, es que está fuera de toda duda su pertenencia a la cultura aborigen. Otra cuestión es la de su significado cultural, al que si bien solo es posible acceder en un nivel hipotético, existe el suficiente apoyo de información en los contextos de algunos de los yacimientos rupestres insulares (Jiménez Gómez 1996a).

En la zona del N.E., que aquí se estudia, la necrópolis del Hoyo de los Muertos proporcionó un tablón funerario que portaba una inscripción y varios signos del líbico-bereberes, acompañado de restos humanos (Diego Cuscoy et alii. 1975), en un contexto claramente aborigen que permite que los grabados puedan ser adscritos a las creencias religiosas y presupuestos socio-económicos. Esta asociación con el mundo funerario y prácticas mágico-religiosas también es constatable en El Julan (Frontera), al SW de la isla. Un asentamiento cuyos vestigios arqueológicos parecen mostrar esta misma significación: aras de sacrificio que contienen restos de animales quemados, cuevas sepulcrales, concheros, construcciones circulares y una gran extensión de grabados rupestres de tipo geométrico que se combinan con un reducido número de inscripciones líbico-berberes.

Otro elemento con el que se asocia a estos grabados es el agua; esto ocurre, como ya hemos indicado, en las estaciones que se localizan a lo largo de los cursos de los barrancos de la zona nororiental; pero existe un yacimiento donde esta relación no solo es evidente, es indisoluble: la Cueva del Agua o de Letime (Isora, Valverde). Se trata de la única estación donde los grabados están en las paredes internas de una cueva, a diferencia del resto del conjunto insular que lo está al aire libre, coincidiendo con uno de los escasos rezumos de agua que existen en la zona (Balbín Behrmann et alii. 1983). Un bien extremadamente escaso en la isla del que las fuentes historigráficas han dejado constancia en repetidas ocasiones, especialmente al describir los ritos de los bimbaches para propiciar de lluvia, en los que el Barranco de Tejeleita, creemos, jugó un papel relevante.

Señalan estas fuentes que El Hierro estaba desprovisto de cursos de agua corriente, y que solo tenía tres manantiales y que el aprovisionamiento de este elemento lo obtenía la población de la lluvia horizontal, especialmente la destilada en el Árbol Santo o Garoé (Abreu Galindo 1940: 58). La vinculación de este elemento con la supervivencia humana y de la vida en general, y la escasez reinante en este medio limitado por su condición insular, ponen de relieve la profunda significación que tubo en esta sociedad. Su inclusión dentro de las creencias y prácticas religiosas quedó recogida en las fuentes históricas originadas de fechas próximas a la conquista. En estas se detalla el carácter de sus divinidades, los lugares donde habitaban, y las ceremonias propiciatorias de la lluvia, cuando esta no caía. Es aquí donde el Barranco de Tejeleita adquiere protagonismo, al ser aquí donde entendemos pudo haber estado ubicada la cueva donde vivía una divinidad secundaria, que denominaban Aranfaybo que representaban bajo la forma de un cochino, considerado como mediador entre los hombres y los dioses y como dador de lluvia. Dicen estos documentos que a esta cueva la llamaban "asteheyta" y se ubicaba en un lugar conocido por Tacuytunta (Abreu Galindo 1940: 62).

Algunos estudios de toponimia aborigen señalan la voz Tejeleita como una derivación Asteheita (Álvarez Delgado 1946: 11). Esta información se complementa perfectamente con la información arqueológica e historiográfica que, entendemos, corrobora la identificación de esta oquedad con la denominada Cueva de La Pólvora que se abre en el origen de este Barranco de Tejeleita. Dice la tradición oral que allí existía un templo aborigen; esto debió ser cierto, aunque desconocemos la realidad arqueológica del lugar, ya que fue en el interior de esta cueva donde los colonos que fundan la Villa de Valverde edifican en su interior su primera ermita que dedican a Santiago. Se trata de un proceder extraño causado, no por la falta de sitio donde erigir un templo sino por lo que eran las pautas de cristianización de lo pagano, la destrucción de 
los valores simbólicos, de la cohesión social y, en definitiva, una estrategia de disuasión e integración de la población vencida (Jiménez Gómez 1993: 120).

Como ya hemos dicho Tejeleita y otros barrancos cercanos, además de estar en zona de pastos, son barrancos de gran envergadura dotados de profundos saltos de agua que dan origen la charcas donde el agua queda retenida durante largas temporadas; coincidiendo con éstas, en sus proximidades, se encuentran concentraciones de grabados rupestres que vienen a reafirmar la correlación que existe entre ambos. Es también por ello que, teniendo en cuenta que en la concepción que los aborígenes tenían de sus dioses principales éstos no podían ser representados, los innumerables motivos en forma de óvalo que se encuentran a lo largo de las estaciones del barranco, bien geminados, dispuestos en parejas de forma paralela, o compuestos por un apéndice que se proyecta al exterior de forma ondulante, podrían interpretarse como podomorfos, tanto huellas de pies como de calzado que denotan la presencia de los dioses en estos lugares. Una cuestión que muestra como la conformación de las creencias hunde sus raíces en las bases de la supervivencia y se manifiestan adquiriendo las formas y las cualidades de aquellos recursos que son el principal sustento del hombre que las concibe.

Por último, la búsqueda de una cronología para estas manifestaciones es otra de las cuestiones por esclarecer, así como la aún oscura dinámica y fecha del primer poblamiento de las islas. Las fechas absolutas conocidas para datar los inicios del poblamiento prehistórico de El Hierro no son suficientemente todavía para abordar con cierta credibilidad este tema y, mucho menos, las circunstancias de su colonización. Investigaciones recientes señalan que el alfabeto líbico-bereber compartió, en el norte de África, espacio y tiempo con otros alfabetos: en sus inicios lo hizo con el Púnico, al que conciben como posible fuente de inspiración; después con el latino, desde ese momento hasta el fin de la Antigüedad; y con el Árabe, desde el siglo VII hasta hoy entre los Tuareg. Se plantea, a su vez, que en algún momento después del siglo III ó II a.C, la posible llegada de gentes procedentes del reino de Numidia y por tanto portadoras del alfabeto Canario Occidental, que sería el más antiguos empleado en las islas (Belmonte et alii. 1998: 11).

Es evidente, como puede observarse, que se trata de un dilatado periodo en el que no se ha podido acotar el momento en que este tipo de escritura cae en desuso en las zonas de posible procedencia, si bien R. Springuer supone que su empleo no debió prolongarse mucho más allá de la caída del Imperio Romano.

En esta misma dirección existen otras hipótesis de trabajo sobre la fecha de llegada de los portadores de este alfabeto. Entre los planteamientos más recientes M. Hernández Pérez (1981) sitúa este acontecimiento en torno a los inicios de esta Era, aunque no descarta la posibilidad de que también puedan ser posteriores a la conquista. A. Beltrán Martínez (1971), supone que algunos deben ser anteriores al siglo III a.C. y, otros de épocas recientes.

Esta amplitud cronológica junto con escaso conocimiento que se posee sobre el momento o momentos de llegada de los primeros colonos de El Hierro no permite contrastar esta información y, en consecuencia, plantear unas fechas certeras para esta manifestación cultural. De forma específica solo se está en condiciones de tomar en consideración las dos fechas obtenidas del análisis radicarbónico de una muestra de madera procedentes de un tablón funerario, procedente de una necrópolis ubicada en el Hoyo de los Muertos (Guarazoca, Valverde) que portaba una inscripción compuesta por signos de esta misma escritura. La fecha corresponde al año 750 d.C, y se complementa con otra obtenida del análisis de restos humanos asociados a este tablón, que se remonta al año 900 d.C. Unas fechas que creemos deben tomarse con cautela debido a la contaminación que con toda probabilidad debieron sufrir a causa del largo abandono y exposición a la intemperie de estos vestigios, producto de un hallazgo fortuito. Fue decisiva, no obstante, la presencia de estas inscripciones en un contexto claramente aborigen permitiendo conocer la autoría de las mismas, rebatido con anterioridad (Verneau 1981: 97; Álvarez Delgado 1964: 393). 


\section{BIBLIOGRAFÍA}

ABREU GALINDO, Fr. J. (1940): Historia de la Conquista de las Siete Islas Canarias. Santa Cruz de Tenerife.

ÁLVAREZDELGADO, J. (1964): “Ecero. Notas lingüísticas sobre El Hierro”, Revista de Historia Canaria XII: 10-18. La Laguna.

(1964): Inscripciones líbicas de Canarias. Ensayo de interpretación Líbica. La Laguna de Tenerife. BELMONTE, J.A, R. SPRINGER BUNK y PERERA BETHENCOURT, A.M. (1998): “Análisis estadístico y estudio comparativo de las escrituras líbico-bereberes de las Islas Canarias. El noroeste de África y El Sahara", Revista de la Academia Canaria de Ciencias X, 2-3: 9-33.

BELTRÁN MARTÍNEZ, A. (1971): "El arte rupestre y las relaciones atlánticas", Anuario de Estudios Atlánticos 17: 281-306. (Madrid-Las Palmas).

DARIAS PADRÓN, D. (1980): Noticias Generales sobre la Isla del Hierro. Ediciones Goya. Santa Cruz de Tenerife.

DIEGO CUSCOY, L. y GALAND, L. (1975): “La Necrópolis del Hoyo de los Muertos (Guarazoca. El Hierro)", Noticiario Arqueológico Hispánico. Prehistoria 4: 11-33. Madrid.

FERNÁNDEZ-PELLO MARTÍN, L. (1989): Los paisajes naturales de la Usla de El Hierro. Santa Cruz de Tenerife.

HERNÁNDEZ PÉREZ, M.S. (1981): Grabados rupestres del Archipiélago Canario. Colección "La Guagua", 34. Las Palmas de Gran Canaria.

JIMÉNEZ GÓMEZ, M.C. (1993): El Hierro y los bimbaches. Prehistoria de Canarias 6. Sta. Cruz de Tenerife. _ (1996a): "Las manifestaciones rupestres de El Hierro", en Manifestaciones rupestres de las Islas Canarias. Dirección General de Patrimonio Histórico. Santa Cruz de Tenerife.

— (1996b): "La estación rupestre de La Candia, El Hierro (Islas Canarias)", Complutum Extra 6: 263-277. (1996c): "La estación de grabados rupestres de La Caleta, Isla de El Hierro. Canarias", Tabona. Revista de Prehistoria y de Arqueología IX: 99-123. Universidad de La Laguna.

RUIZ GONZÁLEZ, T.; SÁNCHEZ PERERA, S. y SPRINGER BUNK, R. (2000): "Nuevas inscripciones líbico-bereberes de la Isla de El Hierro", El Museo Canario, LV. Madrid. pp.27-57.

TEJERA GASPAR, A. (1993): "Les inscriptios libiques-bereberes des îlles Canaries", Memoire della Societá Italiana di Scienze Naturali e del Museo Civico di Storia Naturale de Milano XXV, fascícolo II: 381-385, Milano.

VERNEAU, R. (1882): “Les inscriptions lapidaires de l'Ärchipel Canarien”. Revue d'Etnographie I: 273-287. Paris.

(1887): Rapport sur une mission scientifique dans l'Ärchipel Canarien. Paris. 

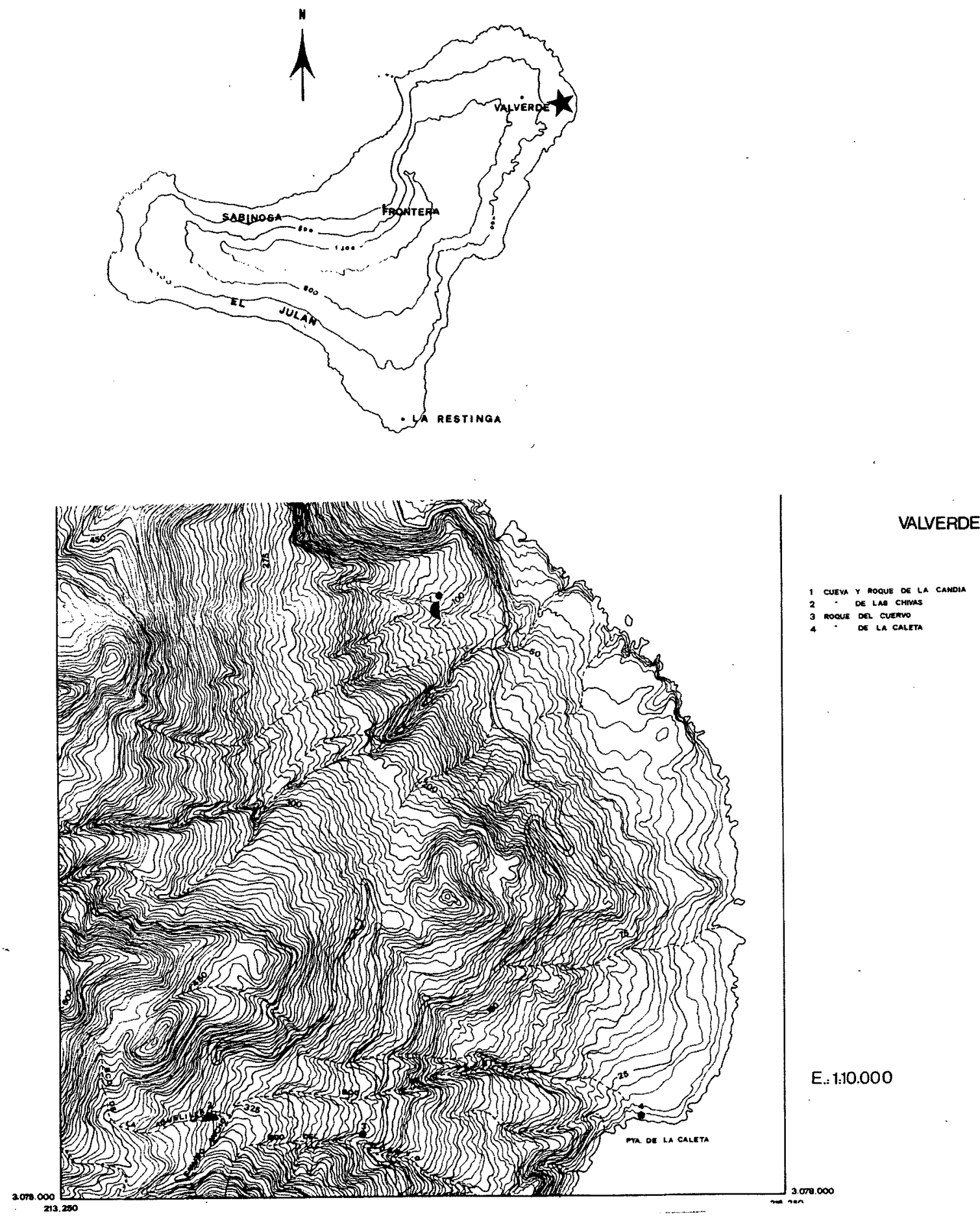

Figura 1. Isla de El Hierro con indicación de la estación de Tejeleita. 2. Principales estaciones rupestres nordorientales. 

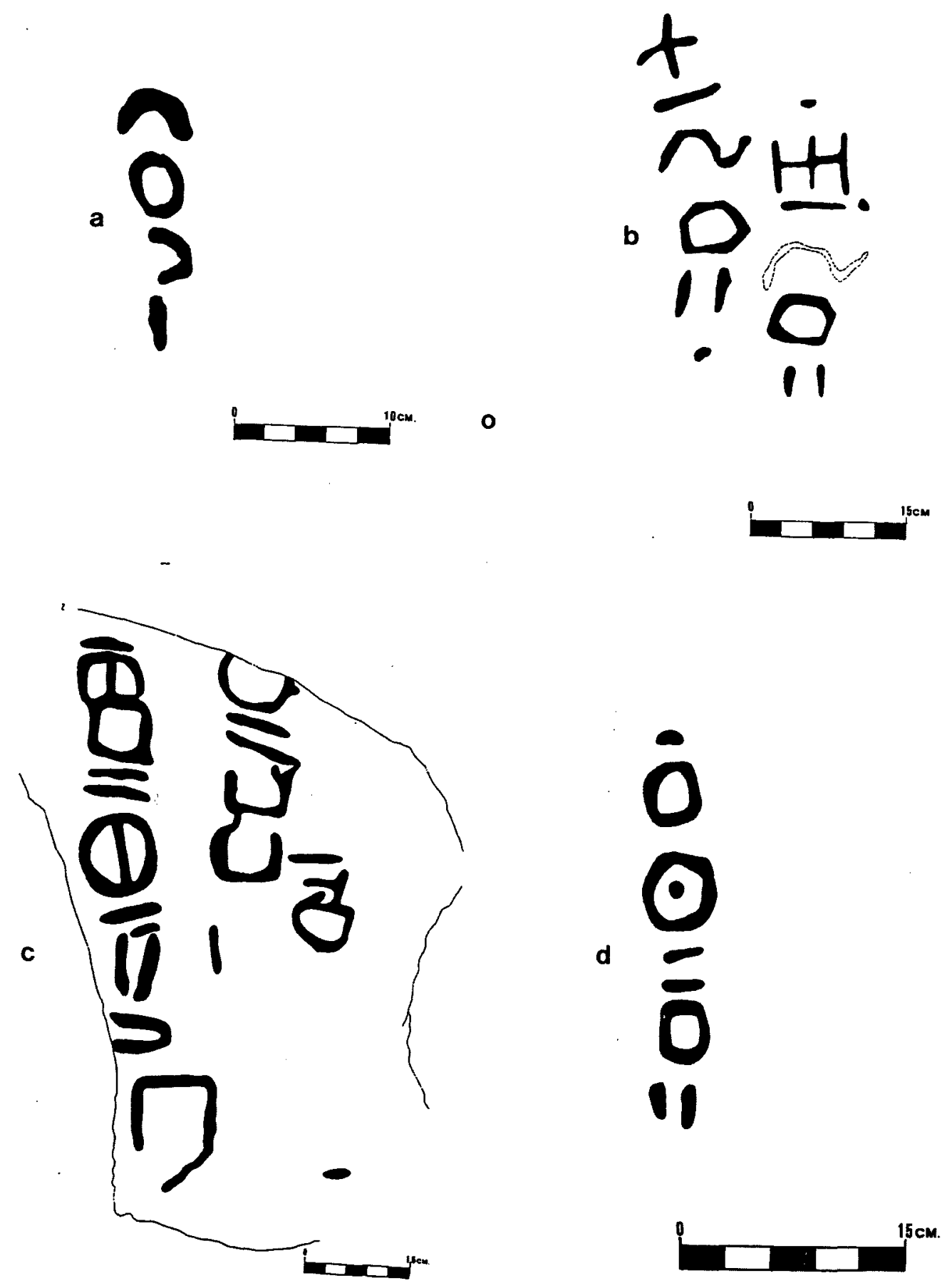

Figura 2. a. Camino Ancho: Estación 1 (panel 1). Tejeleita: b. Estación 2 (pan.1). c. Estación 2. (pan.5). d. Estación 6. 

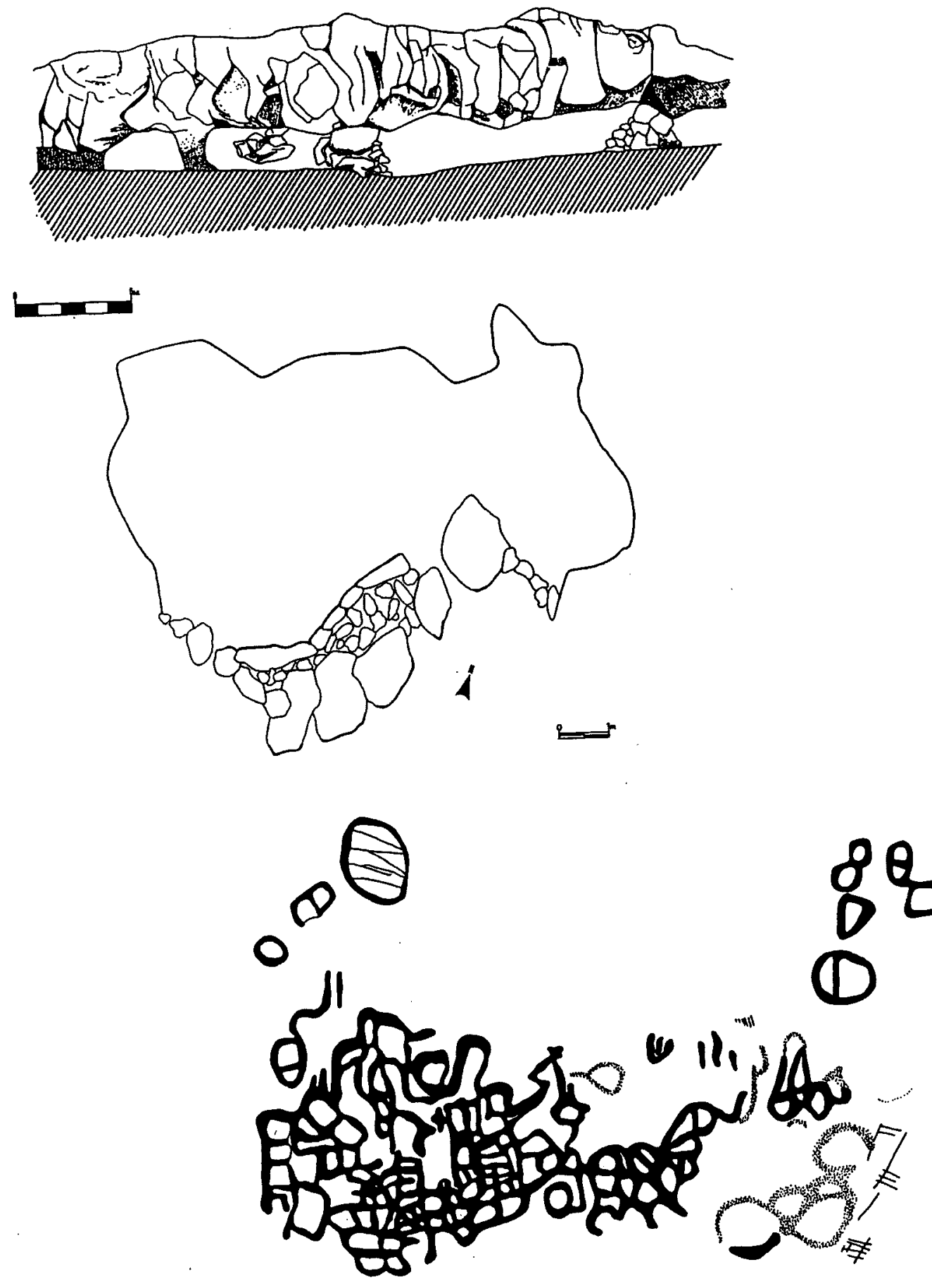

Figura 3. La Aguililla: alzado, planta y panel. 

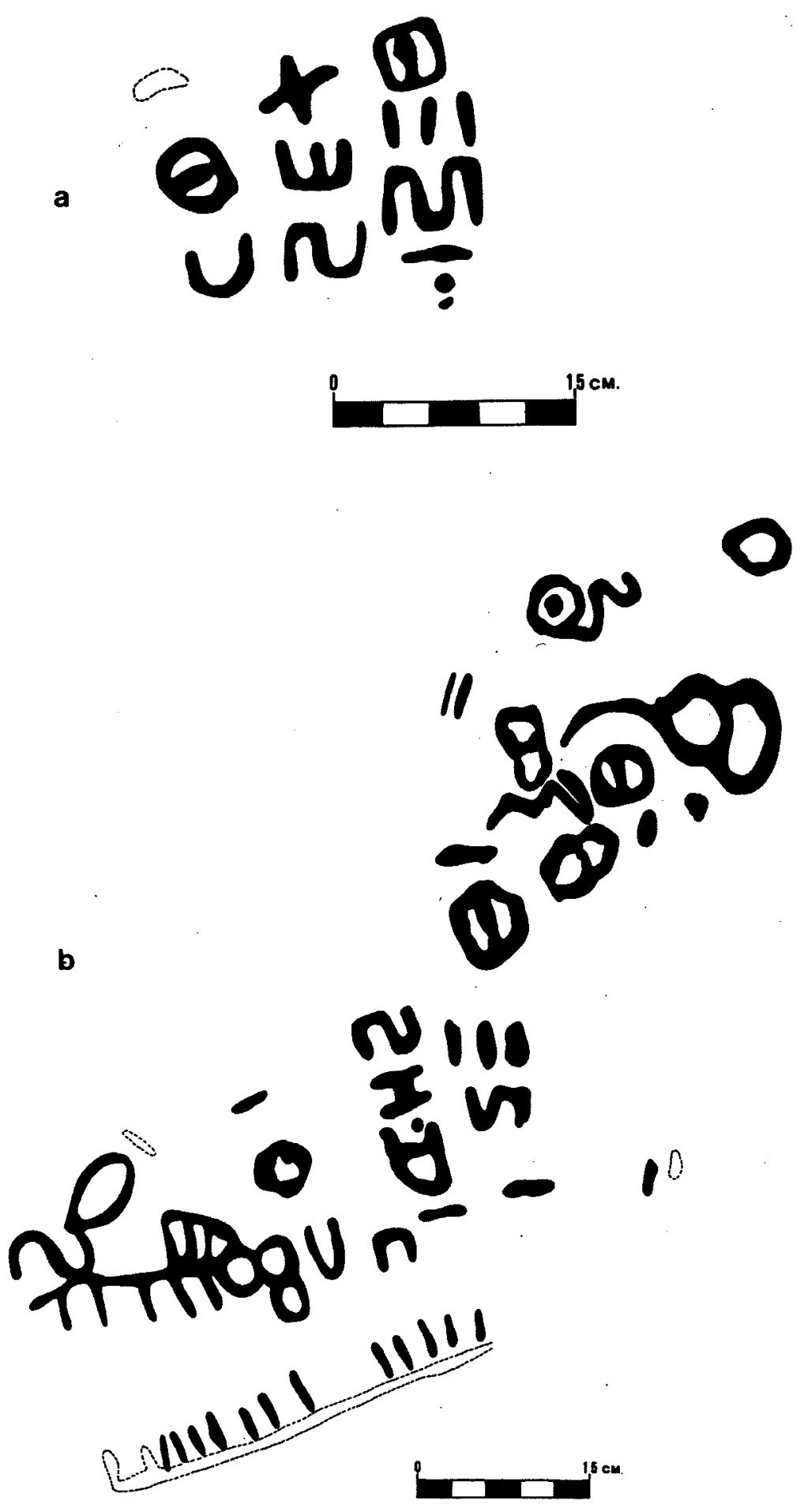

Figura 4. Tejeleita: a. Estación 3 (pan. 2); b. Estación 3 (pan. 1). 

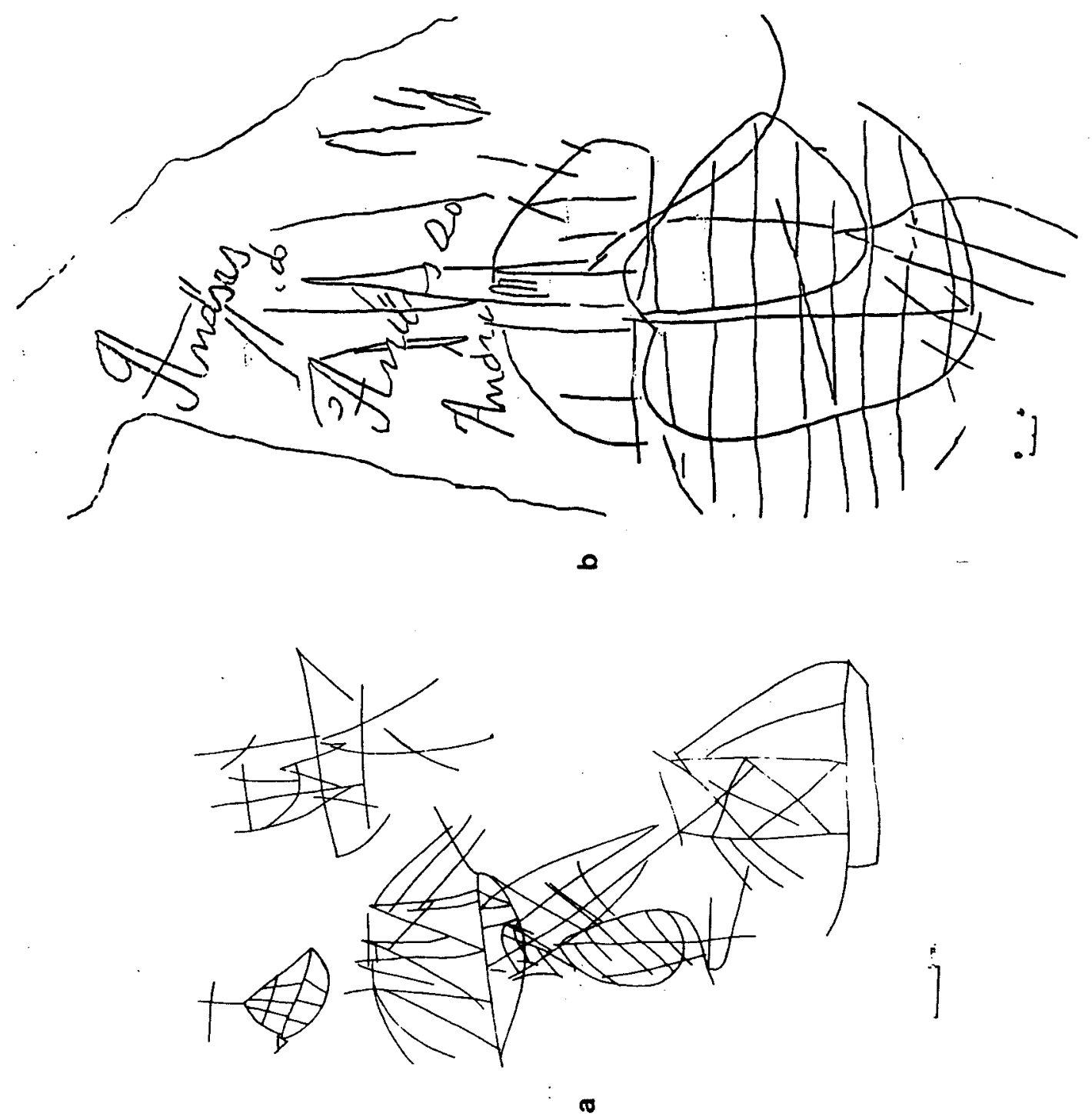

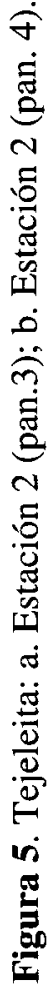



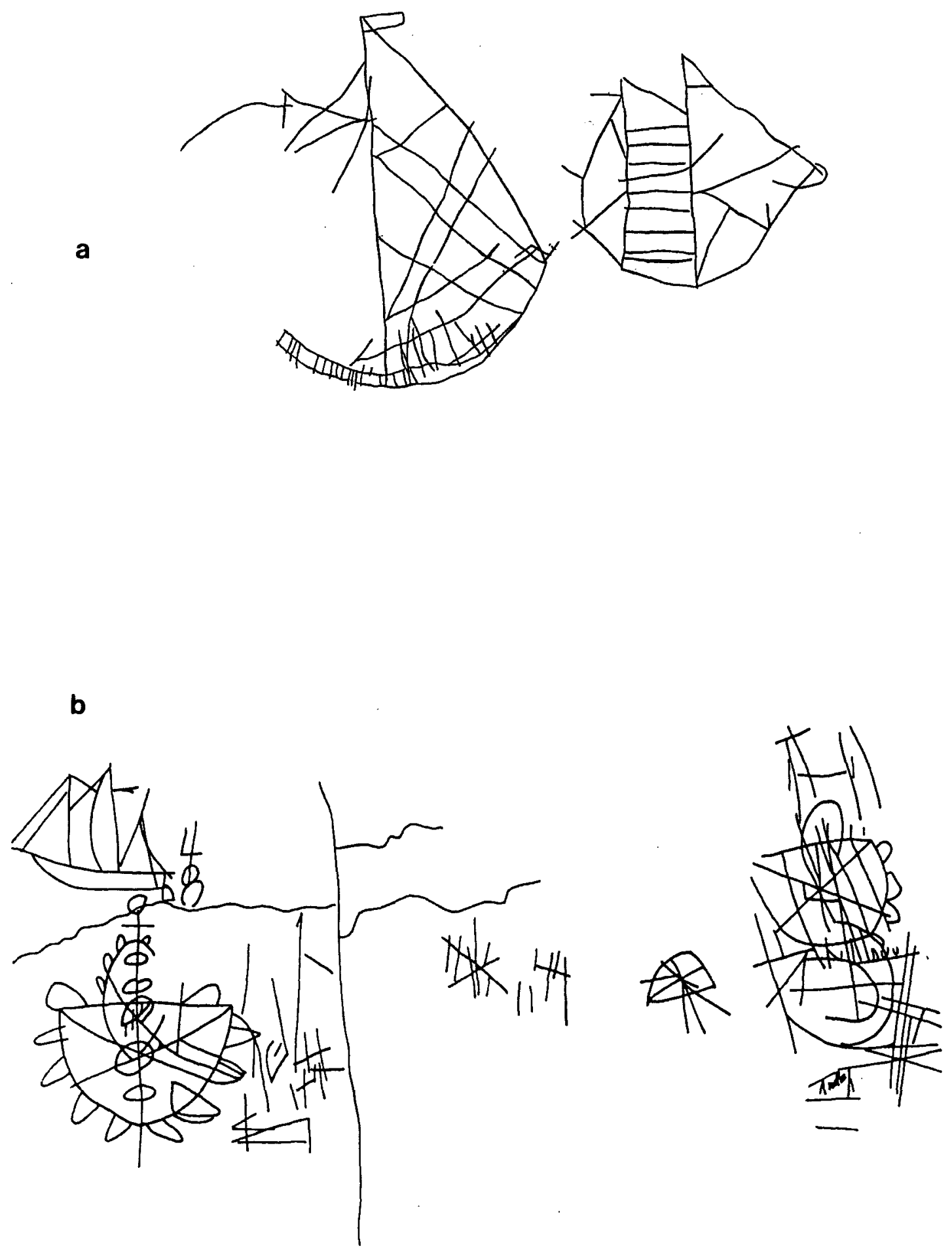

Figura 6. Tejeleita: a. Estación 5 (pan.1); b. Estación 2 (pan.2). 

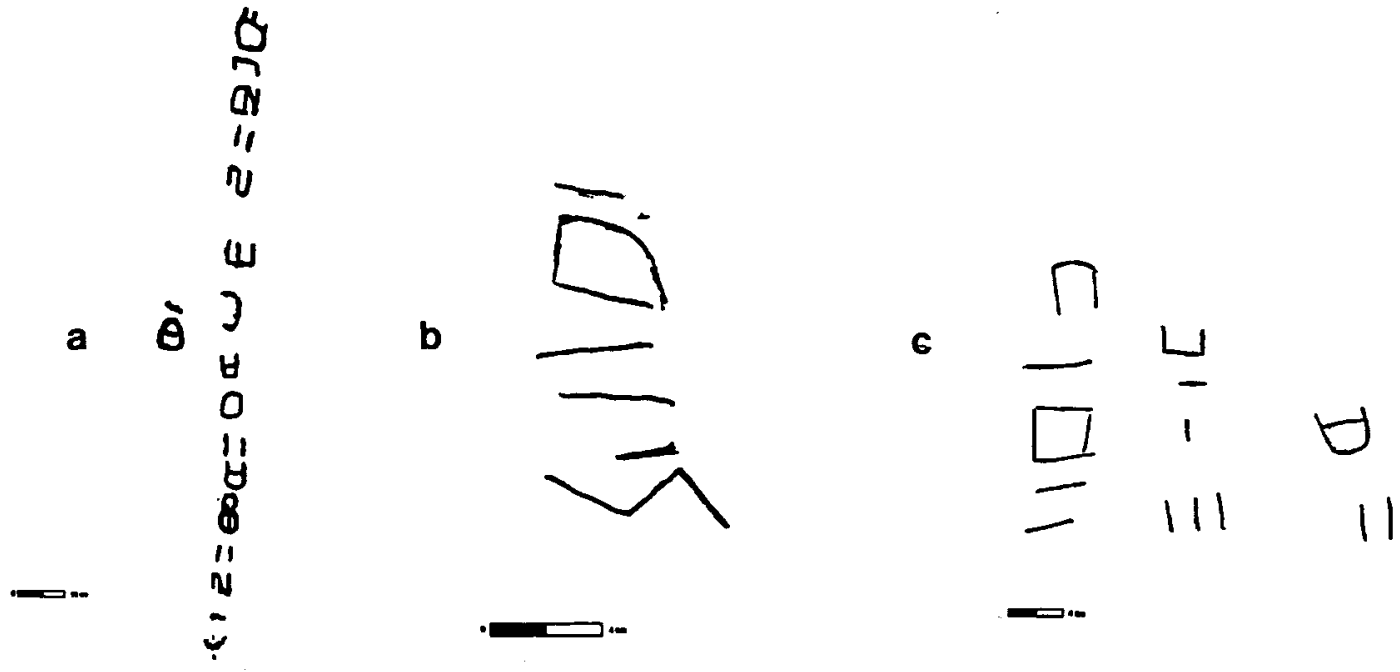

d $\frac{\theta}{\theta}$
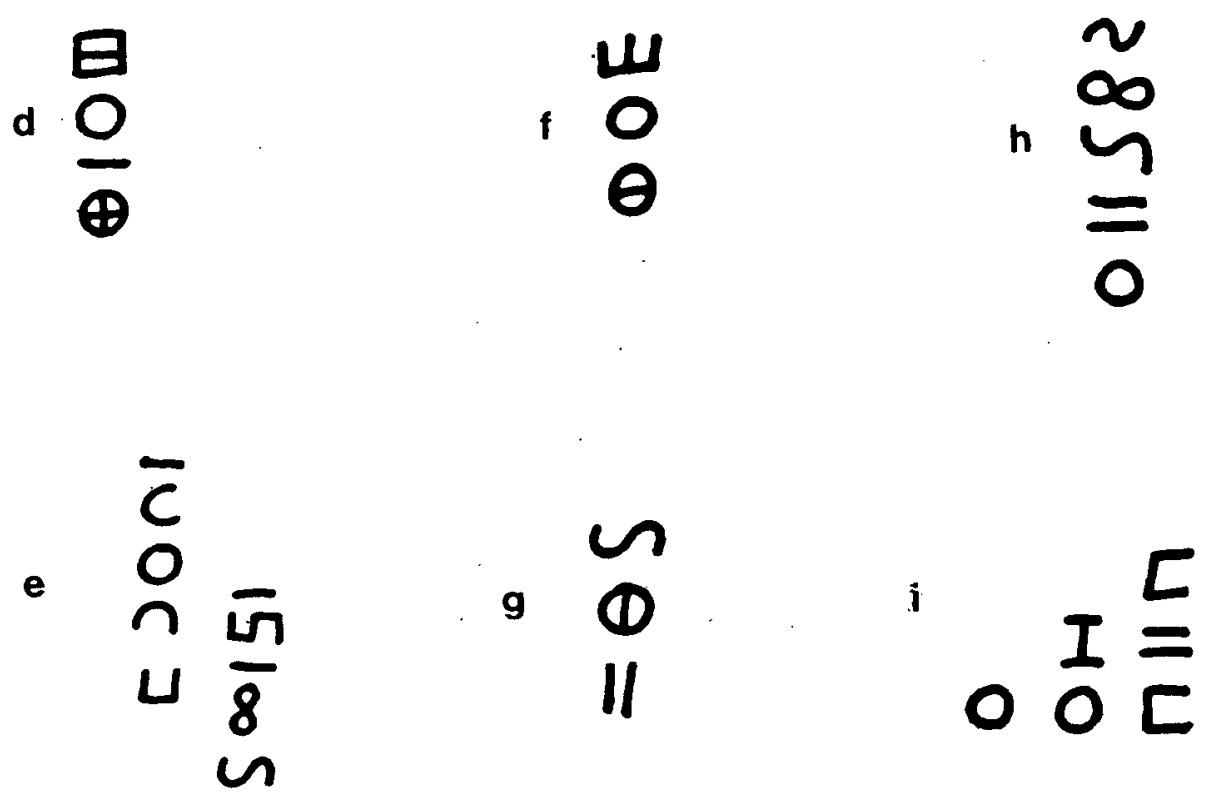

Figura 7. Camino Ancho: a. Estación 2 (pan. 1). Tejeleita: b y c. Estación 1 (panls. 1 y 2) (seg. Ruiz González, T. et alii 2000). Tejeleita. Estación 4: d: pan. 1; e. pan.2. f. pan.3.g. pan. 4. h. pan.5. i. pan.6 (seg. Álvarez Delgado, J.A. 1964). 


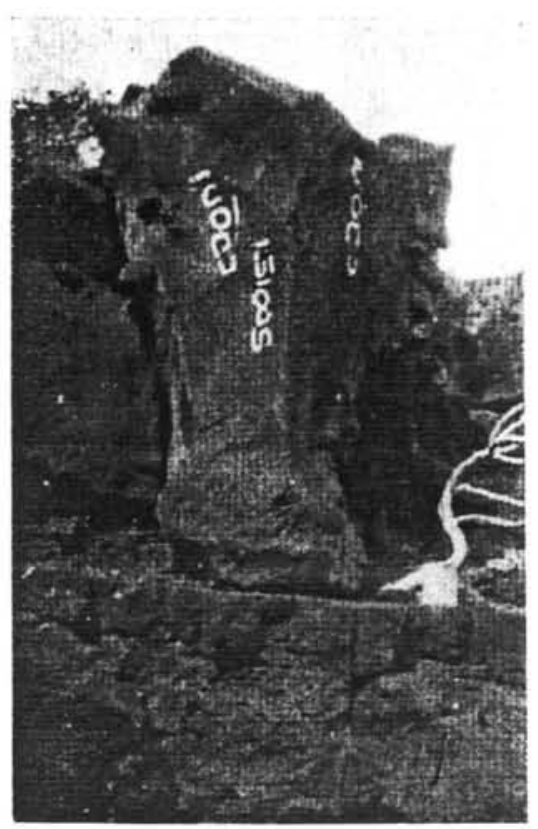

A

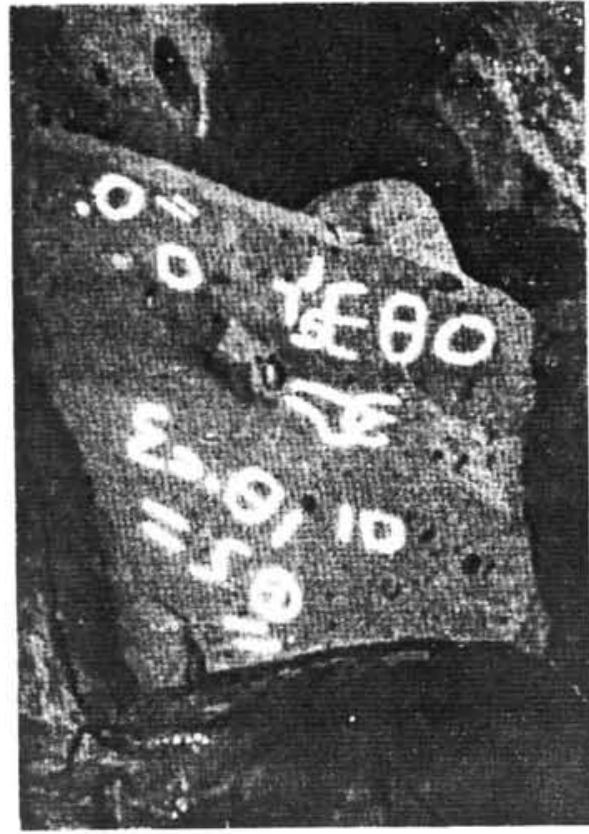

B

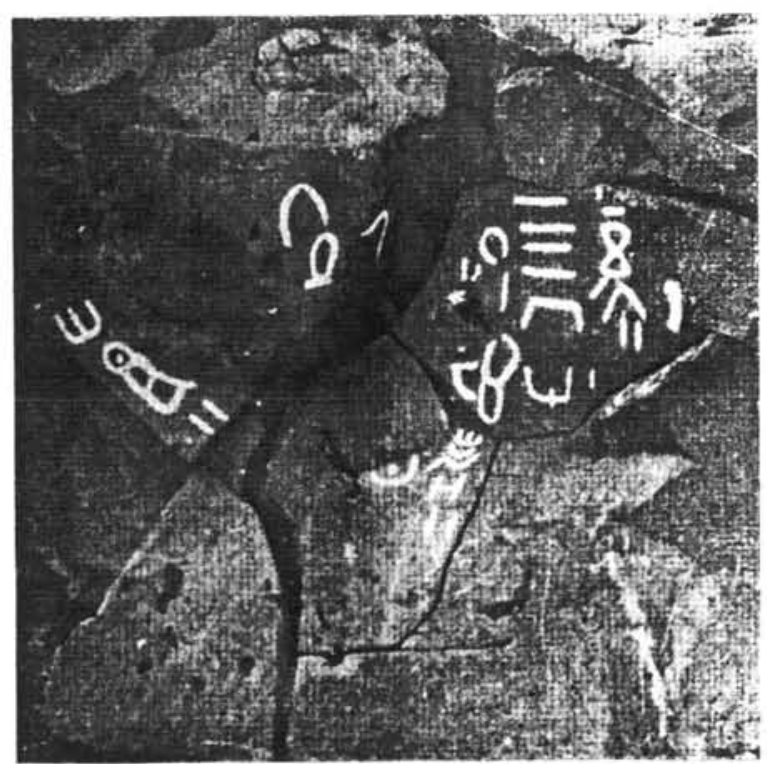

C

Figura 8. Tejeleita. Estación 4. A. panel 2, B. panel 7. C. panel 8 (seg. Álvarez Delgado, J. 1964) 